\title{
Possible Involvement of Nitric Oxide in the Lipopolysaccharide-Induced Impairment of Hepatic Mitochondrial Respiration in vivo
}

\author{
Mitsuyoshi SAI ${ }^{1,2}$, Shozo BabA ${ }^{2}$ and Arata ICHIYAma ${ }^{1}$ \\ ${ }^{1}$ First Department of Biochemistry, and ${ }^{2}$ Second Department of Surgery, Hamamatsu University School of Medicine, Hamamatsu, \\ Shizuoka 431-3192, Japan
}

(Received 25 June 1999; accepted 19 July 1999)

\begin{abstract}
LPS was injected into rats alone or in combination with an NO synthase inhibitor, $\mathrm{N}^{\mathrm{G}}$ monomethyl-L-Arg, or a microsomal P450 inhibitor, SKF525A, and then respiration and phosphorylation in isolated liver mitochondria were measured to gain an insight into the mechanism underlying the LPS-induced mitochondrial injury. Mitochondrial respiration in the presence of ADP or 2,4-DNP was significantly reduced $10 \mathrm{~h}$ after injection of $10-15 \mathrm{mg} /$ $\mathrm{kg}$ LPS, without involving changes in state 4 respiration or the ADP/O ratio. Comparison of the respiration rates with three kinds of substrates, malate/glutamate, succinate and ascorbate/TMPD, in mitochondria from control and LPS-treated rats suggested that not only complex IV but also other components such as complexes I and II are injured by the LPS treatment. Injection of LPS caused an about 2-fold increase in microsomal lipid peroxides as well as massive NO production in the liver, but mitochondrial lipid peroxides were rather reduced. Both $\mathrm{N}^{\mathrm{G}}$-monomethyl-L-Arg and SKF525A were effective in preventing the LPSinduced respiration injury, and the changes in NO production and the lipid peroxide level. Upon prolonged exposure of mitoplasts to FK409, an NO generator, succinate-cytochrome c reductase and cytochrome oxidase were inactivated. It appears that NO, rather than lipid peroxides, plays a predominant role in the LPS-induced impairment of mitochondrial respiration.
\end{abstract}

It is well established that endotoxin, a toxic LPS (lipopolysaccharide) of Gram-negative bacteria,

Correspondence to: Arata Ichiyama at the above address.

TEL: $+81-53-435-2322$

FAX: + 81-53-435-2323

E-MAIL: ichiyama@hama-med.ac.jp

Abbreviations used are: LPS, lipopolysaccharide; 2, 4-DNP, 2,4-dinitrophenol; $\mathrm{NO}$, nitric oxide; $\mathrm{N}^{\mathrm{G}}$. monomethyl-Arg, $\quad \mathrm{N}^{\mathrm{G}}$-monomethyl-L-arginine; DMSO, dimethyl sulfoxide; TMPD, N, N, N', N'tetramethyl-p-phenylenediamine, an oxidationreduction dye known to be reduced with ascorbate and to supply electrons to the mitochondrial respiratory chain at the level of cytochrome c. exerts a wide variety of pathological effects in patients suffering from severe infection, trauma, and complications after major surgery. Defective oxygen utilization at the cellular level despite an apparently adequate oxygen supply (10) appears to be a major basis of the global metabolic dysfunction characteristic of a septic state. Previous studies involving endotoxic rat models revealed that impairment of liver mitochondrial respiration and phosphorylation accounted for the metabolic dysfunction $(16,20)$. The mechanisms underlying the mitochondrial injury induced by NO (nitric oxide) and reactive oxygen species have been studied using isolated mitochondria (7), submitochondrial particles (28), and primary hepatocytes (21) and other types of 
cells (2) in culture. Since an LPS-induced increase in NO production in the liver was recently documented (27), these in vitro studies suggested the role of either $\mathrm{NO}(2,7,21)$ or a reactive oxygen species (28) as a potential mediator of the toxic effect of LPS. Lipid peroxides in membranes have also been implicated in the inhibition of respiration (23).

The present study was performed, based on the information furnished by in vitro studies, to evaluate the impairment of liver mitochondrial respiration caused by in vivo exposure of rats to LPS, with the aim of determining the mediator which plays a major role.

\section{MATERIALS AND METHODS}

Materials. LPS (E. coli 055: B5) was obtained from Difco Laboratories (Detroit, USA), cytochrome c from bovine heart, SKF525A (Proadifen, $\alpha$-phenyl- $\alpha$-propylbenzeneacetic acid-2-[diethylamino] ethyl ester), rotenone, Streptomyces antimycin A, sodium deoxycholate, crystalline BSA and BSA Fraction V from Sigma (St. Louis, USA), rabbit muscle lactate dehydrogenase and Aspergillus nitrate reductase from Boehringer Mannheim (Tokyo, Japan), SDS from BDH Chemicals (Poole, England), and FK409 $(( \pm)-(E)$-ethyl-2-[(E)-hydroxyimino $]-5-n i t r o-3-$ hexeneamide), Tris, TMPD (N, N, N', N'tetramethyl-p-phenylenediamine), thiobarbituric acid, $\mathrm{N}^{\mathrm{G}}$-monomethyl-Arg acetate, $\mathrm{N}$-1-naphthylethylenediamine dihydrochloride, sulfanilamide, dimethyl sulfoxide (DMSO) and 2, 4-DNP from Wako Pure Chemical Industries (Osaka, Japan).

Treatment of animals and preparation of liver mitochondria. Male Wistar rats (150-200 g) were obtained from Japan SLC (Hamamatsu, Japan), and maintained for several days at $25^{\circ} \mathrm{C}$ on a chow diet and water ad libitum. Some rats were injected via a tail vein with $5-15 \mathrm{mg} / \mathrm{kg}$ body weight of LPS in saline. Control rats were injected with the vehicle only. Where indicated, $25 \mathrm{mg} /$ $\mathrm{kg}$ body weight of SKF525A in saline and/or 50 $\mathrm{mg} / \mathrm{kg}$ body weight of $\mathrm{N}^{\mathrm{G}}$-monomethyl-Arg in saline were administered i.p. immediately after the LPS injection. Ten $h$ after the treatment ( 5 or 7.5 $h$ where indicated), the livers were removed and chilled in a buffered sucrose solution $(220 \mathrm{mM}$ mannitol, $70 \mathrm{mM}$ sucrose, $2 \mathrm{mM}$ Hepes, $0.5 \mathrm{~g} / \mathrm{L}$ BSA, pH 7.4). Mitochondrial and microsomal fractions were prepared by differential centrifuga- tion according to Bustamante et al. (6), and de Duve et al. (8), respectively, and adjusted on ice to a concentration of $30 \mathrm{mg}$ protein $/ \mathrm{mL}$. For the preparation of crude mitoplasts, isolated mitochondria were suspended using a glass-Teflon homogenizer in 2-3 volumes the original liver weight of a hypotonic solution $(20 \mathrm{mM} \mathrm{K}$ phosphate containing $0.02 \% \mathrm{BSA}, \mathrm{pH} 7.5$ ). After standing for $20 \mathrm{~min}$ at $0^{\circ} \mathrm{C}$, the suspension was centrifuged at $2,000 \times g$ for $10 \mathrm{~min}$ to precipitate the resultant crude mitoplasts. The protocol of animal treatment was approved by the Institutional Committee for Animal Experimentation, and followed the regulations for animal study.

Determination of oxygen uptake and enzyme activities. $\mathrm{O}_{2}$ uptake in mitochondrial suspensions was measured within 3-4 h after their preparation polarographically with a Clark electrode. Reactions were carried out at $30^{\circ} \mathrm{C}$ in a mixture $(1.0$ $\mathrm{mL}, \mathrm{pH} 7.4$ ) comprising $225 \mathrm{mM}$ sucrose, $10 \mathrm{mM}$ $\mathrm{K}$-phosphate, $20 \mathrm{mM}$ triethanolamine, 5 $\mathrm{mM} \mathrm{MgCl}_{2}, 20 \mathrm{mM} \mathrm{KCl}$, substrate $(5 \mathrm{mM} \mathrm{L}$ malate $/ 2.5 \mathrm{mM}$ L-glutamate, $5 \mathrm{mM}$ succinate or 5 $\mathrm{mM}$ ascorbate $/ 0.2 \mathrm{mM}$ TMPD), $2 \mathrm{mg} / \mathrm{mL}$ isolated mitochondria and $0.4 \mathrm{mM}$ ADP. When ascorbate/TMPD was the substrate, $0.4 \mu \mathrm{M}$ antimycin A was first added to the reaction mixture (about $1 \mathrm{~min}$ prior to the substrate addition) to block backward electron transport from complex III to complexes I and II, allowing selective measurement of complex IV activity with the artificial electron donor. Likewise, reactions with succinate as the substrate were carried out in the presence of $0.2 \mu \mathrm{M}$ rotenone to block backward electron flow from complex II to complex I (Fig. 1). The respiratory rate, respiratory control ratio (state 3 rate/state 4 rate), ADP $/ O$ ratio, and phosphorylation rate (state 3 respiration rate $X$ ADP/O) were calculated as described by Shimahara et al. (20). The rate of uncoupled respiration was measured in the presence of $50 \mu \mathrm{M} 2$, 4-DNP, which was added after measurement of the state 3 and state 4 rates.

The activities of cytochrome oxidase and succinate-cytochrome $\mathrm{c}$ reductase in crude mitoplast preparations were determined at $37^{\circ} \mathrm{C}$ essentially according to Poderoso et al. (18). The reaction mixture $(1.0 \mathrm{~mL})$ for the cytochrome oxidase assay comprised isotonic buffer A (230 $\mathrm{mM}$ mannitol, $70 \mu \mathrm{M}$ sucrose, $5 \mathrm{mM} \mathrm{K}$ phosphate, $0.2 \mathrm{mM}$ EDTA, $30 \mathrm{mM}$ Tris- $\mathrm{HCl}$, pH 7.4), $0.4 \mu \mathrm{M}$ antimycin $\mathrm{A}, 25 \mu \mathrm{M}$ reduced cytochrome $\mathrm{c}$ and $0.1 \mathrm{mg}$ mitoplasts, and that $(1.0$ 


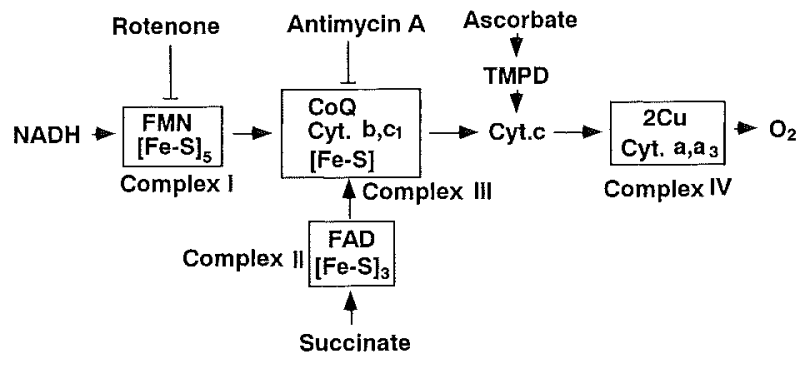

Fig. 1 Electron flow through the mitochondrial respiratory chain. When malate/glutamate is supplied to mitochondria, malate is converted to oxaloacetate by mitochondrial malate dehydrogenase, generating $\mathrm{NADH}$ as a substrate of the respiratory chain, and glutamate serves as a substrate of mitochondrial aspartate aminotransferase to remove oxaloacetate through conversion to aspartate. Thus malate/glutamate supplies electrons to the respiratory chain at the level of complex I. Succinate supplies electrons at the level of complex III via complex II. The oxidation-reduction dye, TMPD, reduced with ascorbate is known to supply electrons at the level of cytochrome $\mathrm{c}$, thus bypassing the first two phosphorylation sites. Rotenone and antimycin A block mitochondrial respiration at the levels of complex I and complex III, respectively. The abbreviations used in this figure are: Cyt., cytochrome; CoQ, coenzyme Q; [Fe-S], iron-sulfur cluster.

$\mathrm{mL}$ ) for succinate-cytochrome $\mathrm{c}$ reductase contained $1 \mathrm{mM} \mathrm{KCN}, 8 \mathrm{mM}$ succinate, $25 \mu \mathrm{M}$ cytochrome $\mathrm{c}$ and $1 \mathrm{mg}$ mitoplasts in isotonic buffer A. The activity of succinate-cytochrome $\mathrm{c}$ reductase was expressed as nmoles of cytochrome c reduced $/ \mathrm{min} / \mathrm{mg}$ protein. The rate of cytochrome oxidase-catalyzed oxidation of reduced cytochrome $\mathrm{c}$ was determined as the pseudo-firstorder reaction constant and expressed as $\mathrm{k}^{\prime} / \mathrm{min} /$ mg protein (25).

Effects of NO on succinate-cytochrome $c$ reductase and cytochrome oxidase activities in mitoplast. FK409, an NO generator with a halflife of about $30 \mathrm{~min}$ (13), was freshly dissolved in DMSO, and a $10 \mu \mathrm{L}$ aliquot was added to $1.0 \mathrm{~mL}$ (final volume) of a reaction mixture. For inhibition of succinate-cytochrome $c$ reductase and cytochrome oxidase, FK 409 was mixed into the reaction mixtures shortly before the reactions were started by the addition of cytochrome $\mathrm{c}$ or its reduced form. In some experiments, the enzyme activities were also determined 10,20,30 and 60 min after the single addition of $0.1 \mathrm{mM}$ (final concentration) FK409 to examine the reversibility of the inhibition. For continuous exposure of mitoplasts to $\mathrm{NO}$, a $10-\mu \mathrm{L}$ aliquot of $10 \mathrm{mM}$ or $50 \mathrm{mM}$ FK409 in DMSO was added at 0-time to $0.99 \mathrm{~mL}$ of a mitoplast suspension $(5 \mathrm{mg}$ protein/ $\mathrm{mL}$ ) in isotonic buffer $\mathrm{A}$, and then the suspension was incubated at $37^{\circ} \mathrm{C}$ for $5 \mathrm{~h}$ with subsequent additions of $5 \mu \mathrm{L}$ each of $10 \mathrm{mM}$ or $50 \mathrm{mM}$ FK 409 at 30 min intervals. A preliminary experiment in which 10 and $50 \mathrm{mM}$ FK409 were separately added to $0.99 \mathrm{~mL}$ of isotonic buffer $A$ according to the above schedule $(10 \mu \mathrm{L}$ at 0 -time and subsequently $5 \mu \mathrm{L}$ each at $30 \mathrm{~min}$ intervals) showed that the nitrite concentrations determined at $30 \mathrm{~min}$ intervals just before each addition of FK409 increased linearly with a small lag of about $1 \mathrm{~h}$, suggesting that the concentration of FK 409 fluctuated in a zigzag manner at $30-\mathrm{min}$ intervals between 0.05 and $0.1 \mathrm{mM}$, and 0.25 and $0.5 \mathrm{mM}$, respectively, throughout the preincubation period. After $0.5,1,2,3$ and $5 \mathrm{~h}$ (before each addition of $5 \mu \mathrm{L}$ FK409) of preincubation of mitoplasts with $0.05-0.1 \mathrm{mM}$ FK $409,20-\mu \mathrm{L}$ and $200-\mu \mathrm{L}$ aliquots of the preincubated mitoplasts were removed, and immediately subjected to assaying of cytochrome oxidase and succinatecytochrome $\mathrm{c}$ reductase, respectively, both assays being carried out in a total volume of $1.0 \mathrm{~mL}$. Therefore, the presumed concentration of FK 409 in the assay mixture for cytochrome oxidase and that for succinate cytochrome $\mathrm{c}$ reductase were 1 $\mu \mathrm{M}$ and $10 \mu \mathrm{M}$, respectively. When the concentration of FK409 in the preincubation mixture was 0.25-0.5 mM, mitoplasts were quickly spun down at $0.5,1,2,3$ and $5 \mathrm{~h}$, washed once with isotonic buffer $\mathrm{A}$ to remove FK409, and then subjected to assaying of cytochrome oxidase and succinatecytochrome c reductase.

Assaying of lipid peroxides. Thiobarbituric acidreactive substances in isolated mitochondria and microsomes were measured, as an index of lipid peroxides, essentially according to the method of Ohkawa et al. (17). For this purpose, isolated mitochondria and microsomes in a buffered sucrose solution were washed once with and suspended in chilled $1.15 \% \mathrm{KCl}$.

Measurement of NO production in the liver. NO production was evaluated as the sum of nitrite and nitrate (22) accumulated in the liver. An excised liver specimen was immediately homogenized in a glass-Teflon homogenizer with 2.7 volumes $(\mathrm{v} / \mathrm{w})$ of $0.1 \mathrm{~N} \mathrm{HCl}$, followed by the addition of 0.3 volume $(\mathrm{v} / \mathrm{w})$ the original liver weight of $60 \%(\mathrm{w} / \mathrm{w})$ perchloric acid and rehomogeniza- 
tion. The supernatant solution obtained on centrifugation $\left(10,000 \times \mathrm{g}, 15 \mathrm{~min}\right.$ at $\left.4^{\circ} \mathrm{C}\right)$ was neutralized with $\mathrm{KOH}$ and then subjected to brief centrifugation at $4^{\circ} \mathrm{C}$ to remove $\mathrm{KClO}_{4}$ formed. Then, the neutralized supernatant was subjected to reaction with nitrate reductase to reduce nitrate to nitrite. The reaction mixture $(1.0 \mathrm{~mL}, \mathrm{pH} 7.5)$ comprised $50 \mathrm{mM}$ Na-phosphate, $0.15 \mathrm{mM}$ NADPH, 0.1 unit nitrate reductase and $200 \mu \mathrm{L}$ of the neutralized supernatant. After $30 \mathrm{~min}$ at $37^{\circ} \mathrm{C}$, $10 \mathrm{mM}$ pyruvate and 10 units lactate dehydrogenase were added, and the incubation was continued for an additional $15 \mathrm{~min}$ to oxidize NADPH, which otherwise would have interfered with the following nitrite determination. Nitrite was then determined spectrophotometrically by means of the Griess reaction (11).

Other methods. The protein concentration in isolated mitochondria and microsomes were estimated by the bicinchoninic acid (BCA) protein assay method after treatment with $0.1 \% \mathrm{Na}$ deoxycholate in $1 \mathrm{~N} \mathrm{NaOH}$. Crystalline BSA was used as the standard. Data are presented as the means \pm standard error for a number of determinations $(n=4-8)$, and were analyzed by the paired or unpaired Student's test. Differences with $P$ values of lower than 0.05 were considered significant.

\section{RESULTS}

\section{Effect of LPS administration on the respiration} of isolated mitochondria.

Previous investigations showed inhibition of the respiration and energy production in the livers of endotoxic rats $(20,23)$. Shimahara et al. (20) observed enhancement of the mitochondrial oxidative and phosphorylative activities in the early stage after the administration of LPS, followed by in the late stage a markedly decreased hepatic energy charge and mitochondrial activities. They suggested that the mitochondrial enhancement in the early stage is a protective mechanism which compensates for the decrease in the hepatic energy charge. In our study, both the state 3 mitochondrial respiration with malate/ glutamate as the substrate and that with succinate increased slightly or were maintained at near normal levels until $5 \mathrm{~h}$ after the injection of 15 $\mathrm{mg} / \mathrm{kg}$ body weight of LPS (Fig. 2). Then the $\mathrm{O}_{2}$ uptake decreased gradually, and $10 \mathrm{~h}$ after the LPS injection, the state 3 respiration was $67-69 \%$ of the 0 -time value (Fig. 2), essentially in good

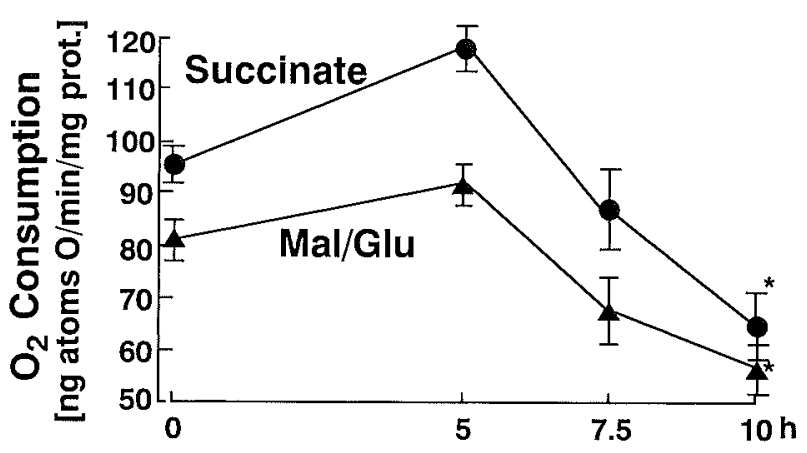

Fig. 2 Changes in state 3 mitochondrial respiration after injection of LPS. Rats were injected with 15 $\mathrm{mg} / \mathrm{kg}$ body weight of LPS at 0 -time. Liver mitochondria were isolated 5, 7.5 and $10 \mathrm{~h}$ later, and then their state 3 respiration was measured with malate/ glutamate (Mal/Glu) or succinate as the substrate, as described under "Experimental Procedures". The data are means \pm SEM for 5 rats.

$* P<0.05$ vs. the corresponding 0 -time levels.

agreement with Shimahara et al. (20). As summarized in Table 1 , although the rate of $\mathrm{O}_{2}$ uptake in the presence of a substrate (malate/ glutamate or succinate), phosphate and ADP (state 3 respiration) was significantly lowered by treatment with $15 \mathrm{mg} / \mathrm{kg}$ body weight of LPS for $10 \mathrm{~h}$, the respiration in the absence of the phosphate acceptor (ADP), the state 4 respiration, was essentially unaffected, leading to a decreased respiratory control ratio. The ADP/O ratio was also unchanged, suggesting that the electron transport per se, rather than oxidative phosphorylation, was primarily affected by the LPS treatment, and indeed the uncoupled respiration in the presence of 2,4-DNP was decreased in mitochondria from LPS-treated rats to about the same extent as state 3 respiration. The phosphorylation rate was also decreased by the LPS treatment, mainly due to the decrease in the state 3 respiration. The values obtained for the respiratory control and ADP/O ratios for the two kinds of respiratory substrates in mitochondria from control and LPS-treated rats indicated that the isolation procedure produced fairly intact, tightly coupled mitochondria (Table 1).

In the experiment shown in Fig. 3, the rate of mitochondrial respiration in the LPS-treated groups $(5,10$ and $15 \mathrm{mg} / \mathrm{kg}, 10 \mathrm{~h})$ was compared with that in the control group using three kinds of respiratory substrates, malate/glutamate, succinate and ascorbate/TMPD. When ascorbate/ 
Table 1 Effects of LPS treatment on respiration and oxidative phosphorylation in isolated mitochondria.

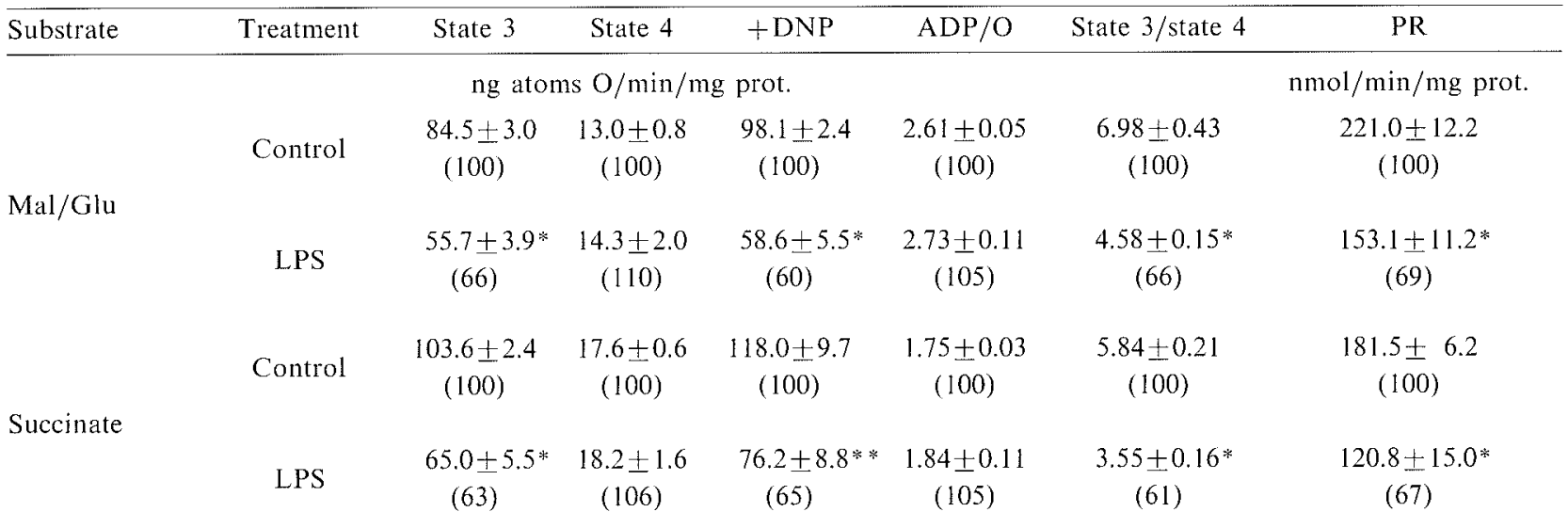

Rats were treated with $15 \mathrm{mg} / \mathrm{kg}$ body weight of LPS and then sacrificed $10 \mathrm{~h}$ later. Control rats were injected with saline. State 3/state 4: respiratory control ratio, PR: phosphorylation rate. The data are means \pm SEM for 5 rats. ${ }^{*} P<0.01,{ }^{*} P<0.05$ ws. control values. Numbers in parentheses: percentages of control values. The abbreviation used in this table: Mal/Glu, malate/glutamate.

TMPD was used as the substrate, a large proportion of the $\mathrm{O}_{2}$ uptake was dependent on the presence of mitochondria. Under the conditions

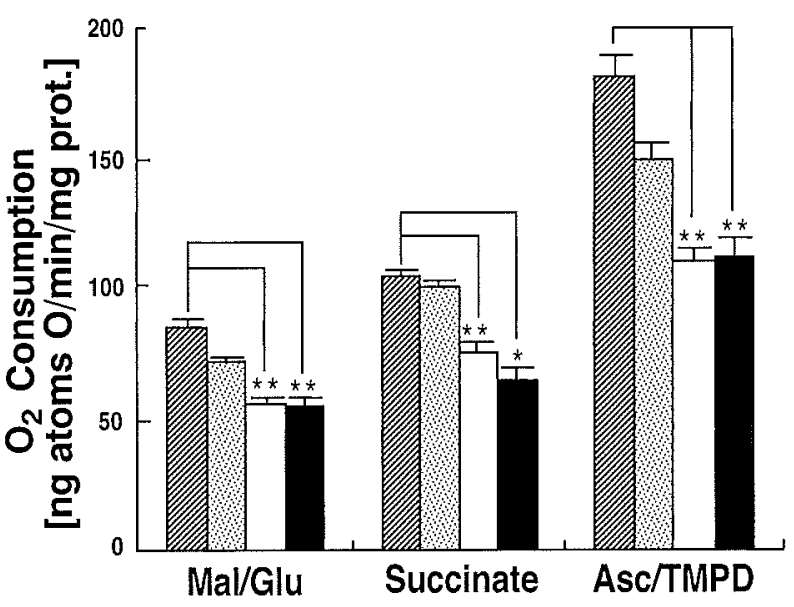

Fig. 3 Effect of the LPS dosage on mitochondrial respiration in the presence of ADP. Rats were injected with $5 \mathrm{mg}, 10 \mathrm{mg}$ or $15 \mathrm{mg} / \mathrm{kg}$ body weight of LPS. Liver mitochondria were isolated $10 \mathrm{~h}$ later, and then their respiration was measured with malate/glutamate (Mal/Glu), succinate or ascorbate/TMPD (Asc/TMPD) as the substrate. The respiration rates in the presence of ADP are presented in this figure. Control rats were injected with saline. 泡, 圆, $\square$, and $\square$ represent the control group, $5 \mathrm{mg}$ / $\mathrm{kg}$ LPS group, $10 \mathrm{mg} / \mathrm{kg}$ LPS group, and $15 \mathrm{mg} / \mathrm{kg}$ LPS group, respectively. $\mathrm{n}=5$ in each group. ${ }^{*} P<$ $0.01,{ }^{*} * P<0.05$ vs. the corresponding control values. used, the rate of $\mathrm{O}_{2}$ uptake caused by reduced TMPD was about $15 \mathrm{ng}$ atoms $\mathrm{O} / \mathrm{min}$ in the absence of mitochondria, and the addition of liver mitochondria $(2 \mathrm{mg})$ from control rats and LPS-treated rats accelerated the $\mathrm{O}_{2}$ uptake to $360-$ 380 and 240-250 $\mathrm{ng}$ atoms $\mathrm{O} / \mathrm{min}$, respectively (Figs. 3 and 7). Although the isolated mitochondria appeared to be fairly intact and tightly coupled according to usual criteria, as far as the respiration with malate/glutamate and that with succinate were concerned (Tables 1 and 2), the rate of mitochondrial respiration with ascorbate/ TMPD as the substrate $\left(\mathrm{O}_{2}\right.$ uptake in the presence of mitochondria - spontaneous $\mathrm{O}_{2}$ uptake) did not respond well to the addition of either ADP or 2,4-DNP for an unknown reason. Therefore, the rate of $\mathrm{O}_{2}$ uptake in the presence of ADP was about the same as that in the presence of 2,4-DNP when ascorbate/TMPD was the substrate, whereas the state 3 respiration rate with malate/ glutamate or succinate was, in general, a little lower than the respective uncoupled respiration rate (Tables 1 and 2). It is evident from Fig. 3 that electron transport from ascorbate/TMPD was also decreased by the LPS treatment, as were the electron flow from malate/glutamate and that from succinate, suggesting that cytochrome oxidase (complex IV) or cytochrome $\mathrm{c}$ is the impaired component of the electron transport chain.

However, complex IV or cytochrome c may not be the sole rate limiting step in mitochondrial 
respiration, because the respiration in control mitochondria with malate/glutamate as the substrate and that with succinate were confined to less than 100 and $120 \mathrm{ng}$ atoms $\mathrm{O} / \mathrm{min} / \mathrm{mg}$, respectively (Tables 1 and 2), although those with ascorbate/TMPD still retained the ability to reduce $\mathrm{O}_{2}$ at the rate of $112 \mathrm{ng}$ atoms $\mathrm{O} / \mathrm{min} / \mathrm{mg}$, even after the LPS treatment (Fig. 3). This level of respiration with malate/glutamate or succinate as the substrate was further reduced by the LPS treatment. Since the activity of cytochrome oxidase is known to be regulated by the concentration of the reduced form of cytochrome $\mathrm{c}$, the above results suggest that the rate of cytochrome c reduction with electrons transported from NADH or succinate was slower than that with reduced TMPD. It is thus further suggested that some other components of the electron transport chain, such as complexes I, II and III, also constitute rate-limiting steps in respiration from malate/glutamate and succinate, and that the rate-limiting steps are impaired, as well as complex IV or cytochrome c, by the LPS treatment. In fact, the cytochrome oxidase and succinatecytochrome $c$ reductase activities measured in four crude mitoplast preparations from the livers of LPS-treated rats $(15 \mathrm{mg} / \mathrm{kg}$ body weight, $10 \mathrm{~h})$ were $70 \% \quad(19.3 \pm 0.9$ vs. $27.4 \pm 1.1 \mathrm{k} / \mathrm{min} / \mathrm{mg}$ protein, $P<0.05)$ and $72 \%(139.2 \pm 2.5$ vs. $192.7 \pm$ $10.8 \mathrm{nmoles} / \mathrm{min} / \mathrm{mg}$ protein, $P<0.05$, one-sided test) of the control values, respectively.

LPS-induced changes in the levels of thiobarbituric acid-reactive substances and NO formation.

It has been reported that lipid peroxides are formed in the liver when experimental animals (rats or mice) are subjected to ischemiareperfusion or LPS treatment, and the lipid peroxide formation has been believed to cause cellular damage resulting in mitochondrial dysfunction $(15,23)$. Sugino et al. observed that the injection of $15 \mathrm{mg} / \mathrm{kg}$ body weight of LPS into mice causes an about 5-fold increase in the liver malondialdehyde level $16 \mathrm{~h}$ after the LPS administration, the increase starting between 8 and $12 \mathrm{~h}$ (23). In our study, thiobarbituric acid-reactive substances were measured as an index of lipid peroxides. When $15 \mathrm{mg} / \mathrm{kg}$ body weight of LPS was injected into rats, thiobarbituric acid-reactive substances gradually increased in liver microsomes, the increase being about 1.4-fold ( $p s$.

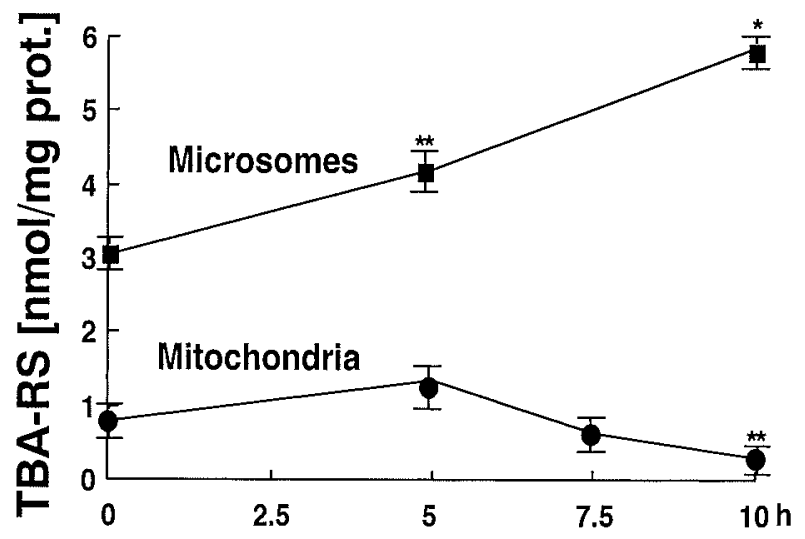

Fig. 4 Levels of thiobarbituric acid-reactive substances after injection of LPS. Rats were injected with $15 \mathrm{mg} / \mathrm{kg}$ body weight of LPS, and then killed $5,7.5$ or $10 \mathrm{~h}$ later. Liver mitochondrial and microsomal fractions were prepared, and thiobarbituric acid-reactive substances (TBA-RS) were measured as described under "Experimental Procedures". The data are means $\pm \mathrm{SEM}$ for 5 rats. ${ }^{*} P<0.01, * * P<$ 0.05 ws. the corresponding 0 -time levels.

0 -time value of $3.03 \pm 0.11$ nmoles $/ \mathrm{mg}$ protein) after $5 \mathrm{~h}$ and 1.9 -fold after $10 \mathrm{~h}$ (Fig. 4). In isolated mitochondria, on the other hand, the level of thiobarbituric acid-reactive substances was slightly increased or unchanged $5 \mathrm{~h}$ after the LPS injection, and then started to decrease to significantly lower levels, the level after $10 \mathrm{~h}$ being about $36 \%$ of the 0 -time value (Fig. 4).

We also measured the accumulation of nitrate and nitrite as an index of LPS-induced NO formation, because NO formation may be responsible, at least in part, for the LPS-induced inhibition of mitochondrial respiration observed in this study. In this experiment, two kinds of enzyme inhibitors were used, one was a specific NO synthase inhibitor, $\mathrm{N}^{\mathrm{G}}$-monomethyl-Arg, and the other was SKF525A. SKF525A is known as an inhibitor of microsomal $\mathrm{P} 450 \mathrm{~s}$, but since NO synthase is a cytochrome $\mathrm{P} 450$ type heme protein, it was thought possible that SKF525A also inhibits the LPS-induced NO production. As shown in Fig. 5, treatment of rats with $15 \mathrm{mg} / \mathrm{kg}$ body weight of LPS for $10 \mathrm{~h}$ led to an enormous (about 10-fold) increase in the level of nitrate plus nitrite, and the LPS-induced increase was effectively, though not completely, prevented by simultaneous injection of either $\mathrm{N}^{\mathrm{G}}$-monomethylArg or SKF525A.

The effects of SKF525A and $\mathrm{N}^{\mathrm{G}}$-monomethyl- 


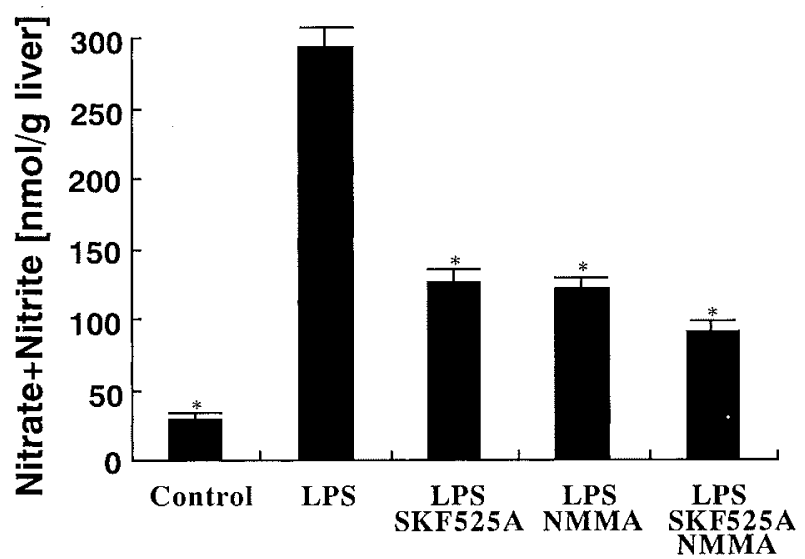

Fig. 5 Accumulation of nitrate and nitrite in the liver in response to LPS treatment. Rats were injected with $15 \mathrm{mg} / \mathrm{kg}$ body weight of LPS, and then killed $10 \mathrm{~h}$ later. Where indicated, $25 \mathrm{mg} / \mathrm{kg}$ SKF525A and/or $50 \mathrm{mg} / \mathrm{kg} \quad \mathrm{N}^{\mathrm{G}}$-monomethyl-Arg (NMMA) were injected simultaneously with the LPS. NO production was evaluated as the sum of nitrate and nitrite accumulated in the liver as described under "Experimental Procedures", because NO has been shown to have a short half-life, about $3-5 \mathrm{sec}$, before it is converted to nitrate and nitrite in biological fluids. Control rats were injected with saline alone. The data are means \pm SEM for 5-8 rats. ${ }^{*} P<0.01$ ws, rats injected with LPS alone.

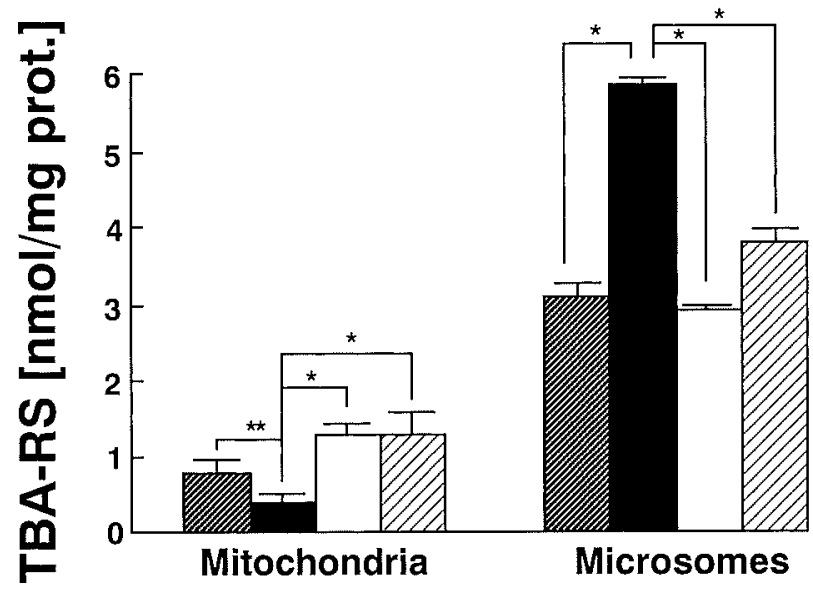

Fig. 6 Effects of SKF525A and $\mathrm{N}^{\mathrm{G}}$-monomethylArg on LPS-induced changes in the levels of thiobarbituric acid-reactive substances in isolated mitochondria and microsomes. Rats were treated as described in the legend to Fig. 5. Liver mitochondrial and microsomal fractions were isolated, and then thiobarbituric acid-reactive substances (TBA-RS) were measured as described under "Experimental Procedures". Rats were injected with saline alone

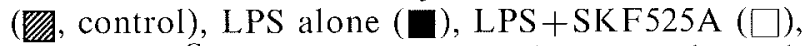
or LPS $+\mathrm{N}^{\mathrm{G}}$-monomethyl-Arg $(\mathbb{Z})$. $\mathrm{n}=5$ in each group. ${ }^{*} P<0.01, * * P<0.05$ ws. rats injected with LPS alone.
Arg on the LPS-induced changes in the levels of thiobarbituric acid-reactive substances in microsomes and mitochondria were also examined. SKF525A, an inhibitor of microsomal P450s, has been shown to reduce $\mathrm{CCl}_{4}$-induced microsomal lipid peroxidation (19). As shown in Fig. 6, SKF525A injected simultaneously with LPS prevented the LPS-induced increase in lipid peroxides in microsomes as expected, and in addition, it counteracted the LPS-induced decrease in mitochondrial lipid peroxides. $\mathrm{N}^{\mathrm{G}}$-MonomethylArg also exerted effects that were quite similar to those of SKF525A.

Effects of SKF525A and $N^{G}$-monomethyl-Arg on LPS-induced impairment of mitochondrial respiration.

We then examined whether or not the LPSinduced impairment of mitochondrial respiration is prevented by simultaneous injection of SKF525A or $\mathrm{N}^{\mathrm{G}}$-monomethyl-Arg. In this experiment, the respiration rate with ascorbate/TMPD again failed to respond well to the addition of either ADP or 2,4-DNP, as in the experiment shown in Fig. 3. Therefore, the respiratory con-
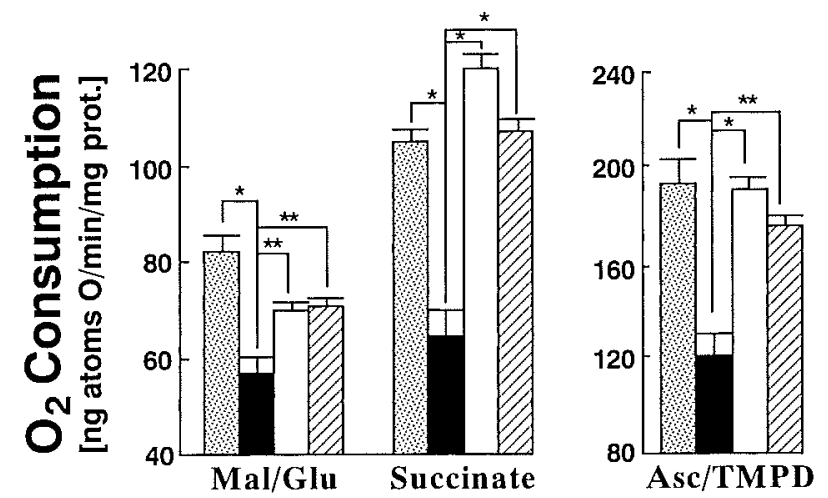

Fig. 7 Effects of SKF525A and $\mathrm{N}^{\mathrm{G}}$-monomethylArg on LPS-induced impairment of mitochondrial respiration. The experimental procedures were as described in the legend to Fig. 6, except that $\mathrm{O}_{2}$ uptake by isolated mitochondria was measured as described under "Experimental Procedures" with malate/glutamate, succinate or ascorbate/TMPD as the respiratory substrate. Control rats were injected with saline alone. The respiration rates in the presence of ADP are plotted on the ordinate. 0 : control, $\square$ : injected with LPS alone, $\square$ : injected with LPS and SKF525A, and injected with LPS and $\mathrm{N}^{\mathrm{G}_{-}}$ monomethyl-Arg. $\mathrm{n}=5,{ }^{*} P<0.0 \mathrm{I}, * * P<0.05$ is. rats injected with LPS alone. 
Table 2 Protection by $N^{G}$-monomethyl-Arg and SKF525A of mitochondrial respiration from LPSionduced impaiment.

\begin{tabular}{|c|c|c|c|c|c|c|c|}
\hline Substrare & Treatment & State 3 & State 4 & $+\mathrm{DNP}$ & $\mathrm{ADP} / \mathrm{O}$ & State $3 /$ state 4 & $\mathrm{PR}$ \\
\hline \multirow{5}{*}{ Mal/Glu } & \multicolumn{6}{|c|}{ ng atoms $\mathrm{O} / \mathrm{min} / \mathrm{mg}$ prot. } & $\mathrm{nmol} / \mathrm{min} / \mathrm{mg}$ prot. \\
\hline & Control & $\begin{array}{l}82.1 \pm 1.4 \\
(100)\end{array}$ & $\begin{array}{l}15.6 \pm 0.7 \\
(100)\end{array}$ & $\begin{array}{l}92.1 \pm 2.5 \\
(100)\end{array}$ & $\begin{array}{c}2.72 \pm 0.05 \\
(100)\end{array}$ & $\begin{array}{c}5.31 \pm 0.22 \\
(100)\end{array}$ & $\begin{array}{c}223.5 \pm 3.9 \\
(100)\end{array}$ \\
\hline & LPS & $\begin{array}{l}55.7 \pm 4.4 \\
(68)\end{array}$ & $\begin{array}{l}15.7 \pm 0.6 \\
(101)\end{array}$ & $\begin{array}{l}59.2 \pm 1.9 \\
(64)\end{array}$ & $\begin{array}{l}2.73 \pm 0.14 \\
(100)\end{array}$ & $\begin{array}{c}3.65 \pm 0.33 \\
(69)\end{array}$ & $\begin{array}{c}154.9 \pm 13.4 \\
(69)\end{array}$ \\
\hline & LPS/SKF525A & $\begin{array}{l}72.4 \pm 4.3 * * \\
(88)\end{array}$ & $\begin{array}{l}16.1 \pm 1.7 \\
(103)\end{array}$ & $\begin{array}{l}92.7 \pm 6.7^{*} \\
(101)\end{array}$ & $\begin{array}{c}2.39 \pm 0.16 \\
(88)\end{array}$ & $\begin{array}{c}4.71 \pm 0.58 \\
(89)\end{array}$ & $\begin{array}{c}171.7 \pm 11.4 \\
(77)\end{array}$ \\
\hline & LPS/NMMA & $\begin{array}{l}71.4 \pm 3.2 * * \\
(87)\end{array}$ & $\begin{array}{c}15.2 \pm 1.4 \\
(97)\end{array}$ & $\begin{array}{l}77.1 \pm 4.6^{* *} \\
\quad(84)\end{array}$ & $\begin{array}{c}2.62 \pm 0.07 \\
(96)\end{array}$ & $\begin{array}{c}4.84 \pm 0.39 \\
(91)\end{array}$ & $\begin{array}{c}187.4 \pm 12.3 \\
(84)\end{array}$ \\
\hline \multirow{4}{*}{ Succinate } & Control & $\begin{array}{l}105.5 \pm 3.6 \\
(100)\end{array}$ & $\begin{array}{c}19.8 \pm 0.6 \\
(100)\end{array}$ & $\begin{array}{c}116.8 \pm 4.9 \\
(100)\end{array}$ & $\begin{array}{l}1.80 \pm 0.05 \\
(100)\end{array}$ & $\begin{array}{c}5.34 \pm 0.17 \\
(100)\end{array}$ & $\begin{array}{l}189.4 \pm 4.5 \\
(100)\end{array}$ \\
\hline & LPS & $\begin{array}{l}66.4 \pm 2.6 \\
(63)\end{array}$ & $\begin{array}{c}23.0 \pm 1.3 \\
(116)\end{array}$ & $\begin{array}{l}71.4 \pm 1.9 \\
(61)\end{array}$ & $\begin{array}{c}1.78 \pm 0.02 \\
(99)\end{array}$ & $\begin{array}{c}2.91 \pm 0.12 \\
(54)\end{array}$ & $\begin{array}{c}118.2 \pm 4.6 \\
(62)\end{array}$ \\
\hline & LPS/SKF525A & $\begin{array}{c}124.4 \pm 8.3^{*} \\
(118)\end{array}$ & $\begin{array}{l}34.8 \pm 2.6^{*} \\
(176)\end{array}$ & $\begin{array}{c}149.4 \pm 8.0^{*} \\
(128)\end{array}$ & $\begin{array}{c}1.54 \pm 0.07 \\
(86)\end{array}$ & $\begin{array}{c}3.59 \pm 0.37 \\
(67)\end{array}$ & $\begin{array}{c}192.4 \pm 17.2^{*} \\
(102)\end{array}$ \\
\hline & LPS/NMMA & $\begin{array}{l}106.8 \pm 6.0^{*} \\
\quad(101)\end{array}$ & $\begin{array}{c}23.9 \pm 2.2 \\
(121)\end{array}$ & $\begin{array}{c}104.3 \pm 7.5^{* *} \\
(89)\end{array}$ & $\begin{array}{c}1.81 \pm 0.03 \\
(101)\end{array}$ & $\begin{array}{c}4.47 \pm 0.14^{*} \\
(84)\end{array}$ & $\begin{array}{c}193.7 \pm 13.3^{*} \\
(102)\end{array}$ \\
\hline
\end{tabular}

The experimental procedures were as described in the legend to Fig. 7. State 3/state 4: respiratory control ratio, PR: phosphorylation rate. The data are means \pm SEM for 5 rats. Numbers in parentheses: percentages of control values. ${ }^{*} P<0.01,{ }^{*} P<0.05$ is. rats injected with LPS alone. The abbreviations used in this table: NMMA, $\mathrm{N}^{\mathrm{G}}$-monomethyl-L-Arg; Mal/Glu, malate/glutamate.

trol ratio, $\mathrm{ADP} / \mathrm{O}$ ratio and phosphorylation rate were calculated only for respiration with malate/ glutamate or succinate as the substrate, and are presented in Table 2. As shown in Fig. 7 and Table 2, both SKF525A and $\mathrm{N}^{\mathrm{G}}$-monomethylArg were quite effective in protecting mitochondrial respiration from the LPS-induced impairment. The protective effects on electron transport from succinate and that from reduced TMPD were nearly complete, although that on respiration with malate/glutamate as the substrate was a little less. These protective effects were exerted without other parameters of respiration and oxidative phosphorylation being affected, except that state 4 respiration with succinate as the substrate was significantly higher than the control level after simultaneous injection of SKF525A with LPS. The higher state 4 respiration rate resulted in a lower respiratory control ratio and a slightly lower ADP/O ratio.

Effects of NO on succinate-cytochrome $c$ reductase and cytochrome oxidase activities in mitoplasts.

We then examined the possibility that NO- induced decreases in the succinate-cytochrome $c$ reductase and cytochrome oxidase activities are involved in the respiratory impairment in the liver of LPS-treated rats. Recently, a reversible inhibition by $\mathrm{NO}$ of the succinate-cytochrome $\mathrm{c}$ reductase and cytochrome oxidase activities in submitochondrial particles has been reported (18). In order to confirm the injurious effects of NO, mitoplasts prepared from mitochondria of normal rat liver were exposed to FK409, an NO generator with a half-life of about $30 \mathrm{~min}$ (13), and then the two enzyme activities were measured. In experiments in which the inhibitory effect was to be examined, FK409 was mixed into the reaction mixtures shortly before the reactions were started by the addition of the substrate, cytochrome $\mathrm{c}$ or its reduced form. As shown in Fig. 8, both the succinate-cytochrome $\mathrm{c}$ reductase and cytochrome oxidase activities were effectively inhibited by FK409, with half maximal inhibition at around $0.05 \mathrm{mM}$. When the assays were performed $10,20,30$ and 60 min after the single addition of $0.1 \mathrm{mM}$ (final concentration) FK409, there was a tendency that both enzyme activities were recovered as the presumed concentration of FK409 and therefore that of generated NO de- 

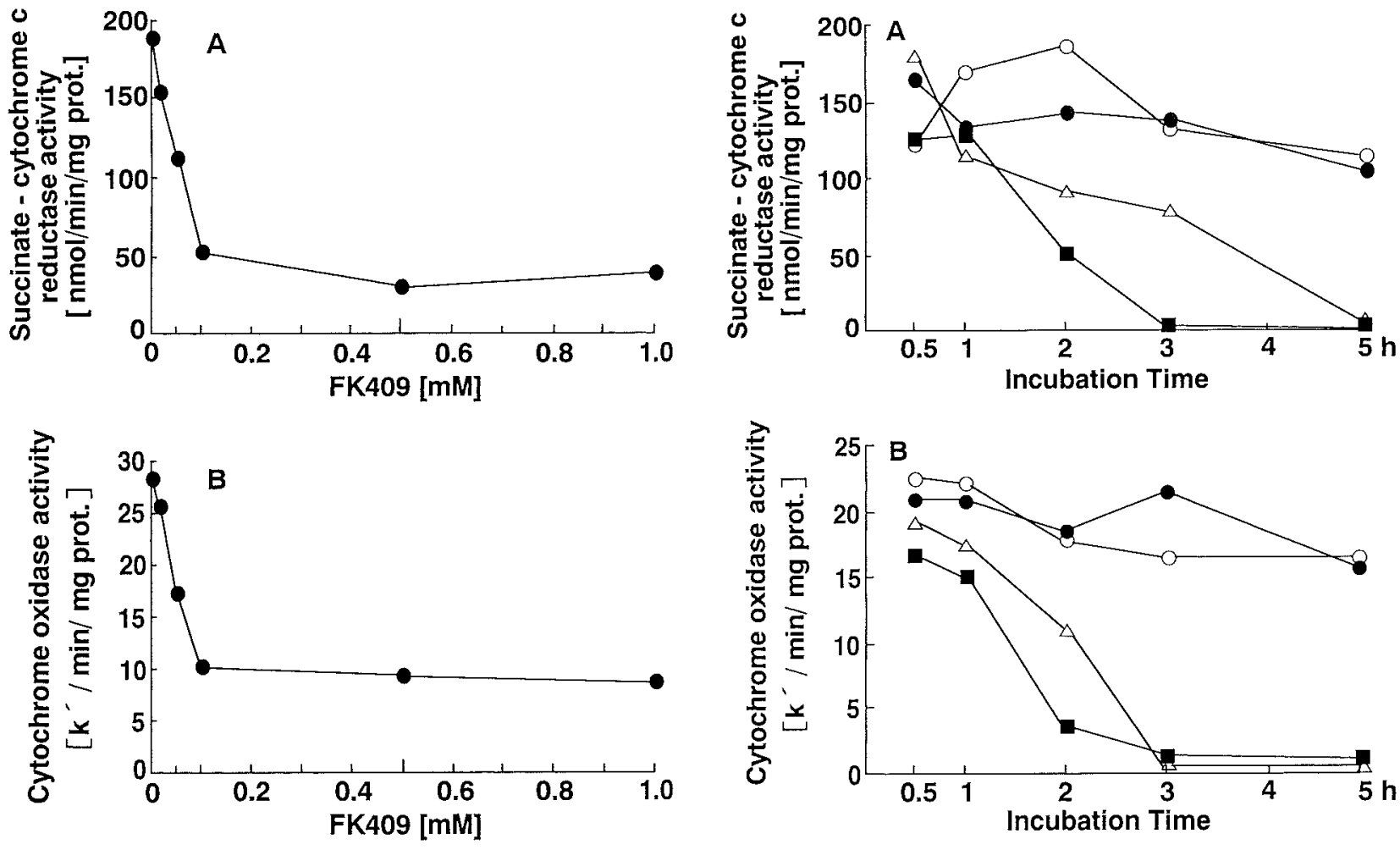

Fig. 8 Inhibition by FK409 of succinatecytochrome $c$ reductase (A) and cytochrome oxidase (B) activities in mitoplasts. Reactions in the presence of various concentrations of FK 409 were carried out as described under "Experimental Procedures" using $1 \mathrm{mg}$ and $0.1 \mathrm{mg}$ (as protein) of mitoplasts for succinate-cytochrome $\mathrm{c}$ reductase and cytochrome oxidase, respectively.

creased. For example, after $60 \mathrm{~min}$, when the concentration of FK 409 was expected to be 0.025 $\mathrm{mM}$ from its half-life of about $30 \mathrm{~min}$, the enzyme activities were $80-100 \%$ of those shortly after the addition of $0.025 \mathrm{mM}$ FK 409, suggesting that the inhibition by FK 409 (possibly by generated NO) was largely reversible.

When the concentration of FK409 in the preincubation mixture was maintained between $0.05-$ $0.1 \mathrm{mM}$ and $0.25-0.5 \mathrm{mM}$ for $0.5-5 \mathrm{~h}$ by repeated additions of FK409 at $30 \mathrm{~min}$ intervals (see Experimental Procedures) and thus mitoplasts were continuously exposed to these concentrations of FK409, on the other hand, both the succinate-cytochrome $\mathrm{c}$ reductase and cytochrome oxidase activities decreased with time, whereas the enzyme activities were fairly stable without the addition of FK409 over the $5 \mathrm{~h}$ preincubation period (Fig. 9). Since the concentration of FK409

Fig. 9 Effect of prolonged exposure to FK409 on succinate-cytochrome $\mathrm{c}$ reductase (A) and cytochrome oxidase (B) activities in mitoplasts. The experimental details are given under "Experimental Procedures". $\bigcirc$ : control (without any addition), and - : control mitoplasts precipitated and washed, $\triangle$ : exposed to $0.05-0.1 \mathrm{mM}$ FK 409, and $\mathbf{m}$ : exposed to $0.25-0.5 \mathrm{mM}$ FK 409, and then precipitated and washed.

carried into the assay mixtures were presumed to be $1 \mu \mathrm{M}$ or less for cytochrome oxidase and 10 $\mu \mathrm{M}$ or less for succinate-cytochrome $\mathrm{c}$ reductase and these concentrations of FK409 were only marginally inhibitory ( $c f$. Fig. 8), these results suggested that the respiratory enzymes were inactivated by the prolonged exposure to FK409 (possibly NO generated therefrom) in vitro.

\section{DISCUSSION}

In the present study, the injection of $10-15 \mathrm{mg} / \mathrm{kg}$ body weight of LPS into rats was shown to injure liver mitochondrial respiration, when mitochondria were isolated $10 \mathrm{~h}$ later and their $\mathrm{O}_{2}$ uptake was analyzed in vitro (Fig. 3). As judged from its effects on various parameters of mitochondrial respiration and oxidative phosphorylation, such 
as the state 3 and state 4 respirations, uncoupled respiration, respiratory control ratio, ADP/O ratio and phosphorylation rate, LPS appeared to exert its effects mainly on electron transport per se, without causing serious uncoupling of phosphorylation from respiration (Table 1). The impaired component of the respiratory chain appears to be cytochrome oxidase or cytochrome c, as judged from the effect of LPS treatment on respiration with reduced TMPD as the substrate (Fig. 3), but the impairment of other components is also suggested by its effects on respiration from $\mathrm{NADH}$ and that from succinate. In fact, both the succinate-cytochrome $\mathrm{c}$ reductase and cytochrome oxidase activities in crude mitoplast preparations prepared from the livers of LPS-treated rats were significantly lower (about $72 \%$ and $70 \%$, respectively) than the control levels. It is possible that NADH-cytochrome $\mathrm{c}$ reductase activity is also impaired by the LPS-treatment, but its reliable measurement as rotenone-sensitive activity was not possible in the present study, because the mitoplast preparations used still exhibited high rotenone-insensitive NADH-cytochrome c reductase activity.

The induction by LPS injection of NO synthase in the liver (14), and the cytotoxic effect of NO (9, 12) have been previously documented. We therefore examined the effects of an NO synthase inhibitor, $\mathrm{N}^{\mathrm{G}}$-monomethyl-Arg, on LPS-induced NO production in the liver and injury to liver mitochondrial respiration. The liver microsomal and mitochondrial lipid peroxide levels and the effect of a microsomal P450 inhibitor, SKF525A, on the respiratory impairment were also examined, because lipid peroxidation has been implicated in LPS-induced hepatic damage (23). LPS injection increased the NO production as much as 10-fold, and $\mathrm{N}^{\mathrm{G}}$-monomethyl-Arg injected simultaneously with LPS suppressed the NO production, as expected (Fig. 5). SKF525A was also effective in preventing the LPS-induced increase in NO production, but this was not surprising because NO synthase is a P450-type heme protein. On the other hand, LPS injection had dual effects on the lipid peroxide levels in the liver, there being an about 2-fold increase in microsomes and a nearly $50 \%$ decrease in mitochondria (Fig. 6). Since liver mitochondrial $\mathrm{Mn}^{2+}$-superoxide dismutase is known to be induced by tumor necrosis factor, an LPSresponsive cytokine (26), the induction of $\mathrm{Mn}^{2+}$ superoxide dismutase may contribute, at least in part, to the LPS-induced decrease in mitochondrial lipid peroxides. Both SKF525A and $\mathrm{N}^{\mathrm{G}}$ monomethyl-Arg injected simultaneously with LPS prevented not only the increase in lipid peroxides in microsomes but also the decrease in mitochondria (Fig. 6). The protective effect of SKF525A against the increase in microsomal lipid peroxides was as expected. In order to fully explain the effects of these two inhibitors on microsomal and mitochondrial lipid peroxides, however, whether or not NO is involved in the induction of $\mathrm{Mn}^{2+}$-superoxide dismutase, and to what extent $\mathrm{NO}$ or NO-derived radicals contribute to the formation of lipid peroxides should be studied further.

Both $\mathrm{N}^{\mathrm{G}}$-monomethyl-Arg and SKF525A were effective in preventing the LPS-induced impairment of mitochondrial respiration, especially that with succinate or ascorbate/TMPD as the substrate, when they were injected into rats simultaneously with LPS (Fig. 7 and Table 2). These results are consistent with the notion that NO is involved in LPS-induced respiratory damage. Mitochondrial respiration as well as the aconitase activity in isolated hepatocytes has been shown to be inhibited by NO at complexes I and II (2). Inhibition by NO in vitro of cytochrome oxidase (complex IV) has also been reported $(2,3,7,18)$, but the inhibition was shown, in most cases, to be reversible $(3,7,18,21)$. In the present study, liver mitochondria were isolated from LPS-treated rats and their respiration rate was measured in vitro. It has been demonstrated that a high steady-state level of LPS in the plasma is attained within $1 \mathrm{~h}$ after LPS injection into mice, and this high level is maintained up to $24 \mathrm{~h} \mathrm{(23).} \mathrm{Thus,} \mathrm{the} \mathrm{liver} \mathrm{in}$ LPS-injected rats was assumed to be continuously exposed to a high level of LPS for nearly the entire experimental period, but the isolation of liver mitochondria required $2.5-3 \mathrm{~h}$. Considering the short half-life of $\mathrm{NO}$, the activities of reversibly inhibited enzymes were presumed to be restored during the mitochondria isolation procedure. Therefore, the impairment of respiration in mitochondria from LPS-treated rats at complex IV and possibly at other components of the electron transport chain suggests that the reversible inhibition is changed to irreversible one during prolonged exposure to LPS. Indeed, when a mitoplast preparation obtained from the livers of normal rats was exposed to FK409, an NO generator, for $1-3 \mathrm{~h}$ at $37^{\circ} \mathrm{C}$, both the succinatecytochrome $\mathrm{c}$ reductase and cytochrome oxidase 
activities decreased gradually (Fig. 9), although the assays for these enzymes were performed after dilution of the preincubation mixture to a marginally inhibitory concentration of FK409 (cf . Fig. 8) or after mitoplasts had been washed to remove FK409. Irreversible damage may occur in vivo due to reactive oxygen species or other radicals generated from $\mathrm{NO}$ or from the mitochondrial respiratory chain as a consequence of the reversible inhibition of cytochrome oxidase (4). Cytochrome oxidase itself has also been shown to act on NO, producing an oxidation product, possibly the toxic $\mathrm{NO}_{2}$ radical, in addition to $\mathrm{N}_{2} \mathrm{O}$ and $\mathrm{NO}_{2}^{-}$(5).

Lipid peroxide formation, especially that of cardiolipin, has been implicated in the mechanism underlying LPS-induced impairment of mitochondrial respiration (2). Since $\mathrm{ONOO}^{-}$and/ or its derivative, $\mathrm{NO}_{2}$, have been shown to be potent activators of lipid peroxidation (1), and in fact $\mathrm{N}^{\mathrm{G}}$-monomethyl-Arg injected simultaneously with LPS effectively prevented the LPS-induced increase in the liver microsomal lipid peroxide levels in our experiment (Fig. 6), it is possible that NO formation is also connected with lipid peroxide formation. However, lipid peroxides produced in isolated mitochondria on treatment with ferrous iron were shown not to cause measurable inhibition of state 3 respiration up to a concentration of 4 nmoles malondialdehyde equivalents per mg protein (24). In our experiment, the state 3 respiration with malate/ glutamate and that with succinate were clearly injured in liver mitochondria isolated $10 \mathrm{~h}$ after injection of $15 \mathrm{mg} / \mathrm{kg}$ body weight of LPS, although mitochondrial lipid peroxides were decreased by the LPS treatment to a level of 0.29 nmole thiobarbituric acid-reactive substance equivalent per mg protein (Figs. 2 and 4). We feel that NO, rather than lipid peroxides, plays a predominant role in the LPS-induced impairment of mitochondrial respiration.

\section{REFERENCES}

1. Beckman J.S., Beckman T.W., Chen J., Marshall P.A. and Freeman B.A. (1990) Apparent hydroxyl radical production by peroxynitrite: Implications for endothelial injury from nitric oxide and superoxide. Proc. Natl. Acad. Sci. U.S.A. 87; 1620-1624.

2. Bolanos J.P., Peuchen S., Heales S.J.R., Land J.M. and Clark J.B. (1994) Nitric oxide-mediated inhibition of the mitochondrial respiratory chain in cultured astrocytes. $J$. Neurochem. 63; 910-916.

3. Brown G.C. and Cooper C.E. (1994) Nanomolar concen- trations of nitric oxide reversibly inhibit synaptosomal respiration by competing with oxygen at cytochrome oxidase. FEBS Lett. 356; 295-298.

4. Brown G.C. (1995) Nitric oxide regulates mitochondrial respiration and cell functions by inhibiting cytochrome oxidase. FEBS Lett. 369; 136-139.

5. Brudvig G.W., Stevens T.H. and Chan S.I. (1980) Reactions of nitric oxide with cytochrome coxidase. Biochemistry 19; 5275-5285.

6. Bustamante E., Soper J.W. and Pedersen P.L. (1977) A high-yield preparative method for isolation of rat liver mitochondria. Anal. Biochem. 80; 401-408.

7. Cleeter M.W.J., Cooper J.M., Darley-Usmar V.M., Moncada S. and Schapira A.H.V. (1994) Reversible inhibition of cytochrome $c$ oxidase, the terminal enzyme of the mitochondrial respiratory chain, by nitric oxide. FEBS Lett. 345; 50-54.

8. de Duve C., Pressman B.C., Gianetto R., Wattiaux R. and Appelmans F. (1955) Tissue fractionation studies: 6. Intracellular distribution patterns of enzymes in rat-liver tissue. Biochem. J. 60; 604-617.

9. Drapier J-C. and Hibbs J.B.Jr. (1988) Differentiation of murine macrophages to express nonspecific cytotoxicity for tumor cells results in L-arginine-dependent inhibition of mitochondrial iron-sulfur enzymes in the macrophage effector cells. J. Immunol. 140; 2829-2838.

10. Duff J.H., Groves A.C., Mclean A.P., LaPointe R. and MacLean L.D. (1969) Defective oxygen consumption in septic shock. Surg. Gynecol. Obestet. 128; 1051-1060.

11. Green L.C., Wagner D.A., Glogowski J., Skipper P.L. Wishnok J.S. and Tannenbaum S.R. (1982) Analysis of nitrate, nitrite, and $\left[{ }^{15} \mathrm{~N}\right]$ nitrate in biological fluids. Anal. Biochem. 126; 131-138.

12. Hibbs J.B.Jr., Taintor R.R. and Vavrin Z. (1987) Macrophage cytotoxicity: Role for L-arginine deiminase and imino nitrogen oxidation to nitrite. Science 235; 473-476.

13. Kita Y., Hirasawa Y., Maeda K., Nishio M. and Yoshida K. (1994) Spontaneous nitric oxide release accounts for the potent pharmacological actions of FK409. Eur. J. Pharmacol. 257; 123-130.

14. Knowles R.G., Merrett M., Salter M. and Moncada S. (1990) Differential induction of brain, lung and liver nitric oxide synthase by endotoxin in the rat. Biochem. J. 270; 833-836.

15. Marubayashi S., Dohi K., Ezaki H., Yamada K, and Kawasaki T. (1983) Preservation of ischemic liver cell Prevention of damage by coenzyme $\mathrm{Q}_{10}$. Transplantation Proc. 15; 1297-1299.

16. Mela L., Bacalzo L.V.Jr. and Miller L.D. (1971) Defective oxidative metabolism of rat liver mitochondria in hemorrhagic and endotoxin shock. Am. I. Physiol. 220; 571-577.

17. Ohkawa H., Ohishi N. and Yagi K. (1979) Assay for lipid peroxides in animal tissues by thiobarbituric acid reaction. Anal. Biochem. 95; 351-358.

18. Poderoso J.J., Carreras M.C., Lisdero C., Riobo N., Schoepfer F. and Boveris A. (1996) Nitric oxide inhibits electron transfer and increases superoxide radical production in rat heart mitochondria and submitochondrial particles. Arch. Biochem. Biophys. 328; 85-92.

19. Rao K.S., Glende E.A.Jr. and Recknagel R.O. (1970) Effect of drug pretreatment on carbon tetrachlorideinduced lipid peroxidation in rat liver microsomal lipids. Exp. Mol. Pathol. 12; 324-331.

20. Shimahara Y., Ozawa K., Ida T., Ukikusa M. and Tobe T. 
(1982) Role of mitochondrial enhancement in maintaining hepatic energy charge level in endotoxin shock. J. Surg. Res. 33; 314-323.

21. Stadler J., Billiar T.R., Curran R.D., Stuehr D.J., Ochoa J. B. and Simmons R.L. (1991) Effect of exogenous and endogenous nitric oxide on mitochondrial respiration of rat hepatocytes. Am. J. Physiol. 260; C910-C916.

22. Stuehr D.J. and Marletta M.A. (1985) Mammalian nitrate biosynthesis: Mouse macrophages produce nitrite and nitrate in response to Escherichia coli lipopolysaccharide. Proc. Natl. Acad. Sci. USA 82; 7738-7742.

23. Sugino K., Dohi K., Yamada K. and Kawasaki T. (1987) The role of lipid peroxidation in endotoxin-induced hepatic damage and the protective effect of antioxidants. Surgery 101; 746-752.

24. Vladimirov Y.A., Olenev V.I., Suslova T.B. and Cheremisina Z.P. (1979) Lipid peroxidation in mitochondrial membrane. Adv. Lipid Res. 17; 173-249.
25. Wharton D.C. and Tzagoloff A. (1967) Cytochrome oxidase from beef heart mitochondria. Methods Enzymol. $10 ; 245-250$.

26. Wong G.H.W. and Goeddel D.V. (1988) Induction of manganous superoxide dismutase by tumor necrosis factor: Possible protective mechanism. Science 242; 941-944.

27. Yoshimura T., Yokoyama H., Fujii S., Takayama F., Oikawa K. and Kamada H. (1996) In vivo EPR detection and imaging of endogenous nitric oxide in lipopolysaccharide-treated mice. Nature Biotechnology 14; 992-994.

28. Zhang Y., Marcillat O., Giulivi C., Ernster L. and Davies K.J.A. (1990) The oxidative inactivation of mitochondrial electron transport chain components and ATPase. J. Biol. Chem. 265; 16330-16336. 